ARTICLE

\title{
Calcium isotopic ecology of Turkana Basin hominins
}

Jeremy E. Martin (10 ${ }^{1 凶}$, Théo Tacail (10 ${ }^{2}$, José Braga (1) ${ }^{3,4}$, Thure E. Cerling (1D ${ }^{5}$ \& Vincent Balter (ID ${ }^{1}$

Diet is a major driver of hominin evolution, but most of the geochemical evidence relies on carbon isotopes $\left(\delta^{13} \mathrm{C}\right)$. Here, we report enamel stable calcium isotope $\left(\delta^{44 / 42} \mathrm{Ca}\right)$ values against $\delta^{13} \mathrm{C}$ values for several hominins and co-existing primates in the Turkana Basin area, circa 4 to $2 \mathrm{Ma}$. Australopithecus anamensis clusters with mammal browsers, Kenyanthropus platyops is distinct from $A$. anamensis in foraging into more open environments and the coexisting Theropithecus brumpti encompasses both the grazer and omnivore/carnivore domains. Early Homo is remarkable for its wide distribution in $\delta^{44 / 42} \mathrm{Ca}$ values, possibly reflecting omnivorous and opportunistic preferences. Paranthropus boisei is uniquely distributed in the $\delta^{13} \mathrm{C}$ versus $\delta^{44 / 42} \mathrm{Ca}$ iso-space being distinct from all other hominins from the Turkana Basin area as well as from the co-existing Theropithecus oswaldi. Several hypotheses are explored to discuss the unique $\delta^{44 / 42}$ Ca values of Paranthropus boisei including significant differences observed with $\delta^{44 / 42} \mathrm{Ca}$ values recently reported for $P$. robustus from South Africa, questioning the monophyly of this genus.

\footnotetext{
${ }^{1}$ CNRS, ENSL, LGL-TPE, Univ Lyon, Univ Lyon 1, F-69007 Lyon, France. ${ }^{2}$ Bristol Isotope Group, School of Earth Sciences, University of Bristol, Bristol BS8 1RJ UK. ${ }^{3}$ Evolutionary Studies Institute, University of the Witwatersrand, PO Wits, Johannesburg 2050, South Africa. ${ }^{4}$ CNRS UMR 5288 , University of Paul Sabatier, 37 Allées Jules Guesde, 31000 Toulouse, France. ${ }^{5}$ Department of Geology and Geophysics, University of Utah, Salt Lake City, UT, USA.

凶email: jeremy.martin@ens-lyon.fr
} 
$\mathrm{N}$ on-traditional stable isotopes are providing new avenues of research for exploring the ecology, physiology, and dietary preferences of extinct organisms, including our own lineage. Current evidence for early hominin diet relies on comparative osteology, dental tribology, and geochemistry ${ }^{1-10}$. But in the latter case, collagen nitrogen and its isotopes, a wellused trophic level proxy, are rarely preserved in such ancient (i.e., $>1 \mathrm{Ma}$ ) contexts. While non-traditional isotopes emerge as a new toolkit to paleodietary inference ${ }^{11-15}$, a great deal of the geochemical evidence for early hominin diets relies on carbon isotopes $^{1-9}$ and to a lesser extent on trace element concentrations preserved in mineralized tissues such as fossil bone or teeth ${ }^{16-19}$. The carbon isotopic composition of bioapatite reflects the photosynthetic pathway (i.e., $\mathrm{C}_{3}, \mathrm{C}_{4}$, or CAM) of the ultimate plant source and has been useful for reconstructing past vegetation evolution ${ }^{20}$ and exploring the feeding ecology of African hominins and associated faunas. African hominins cover the whole $\mathrm{C}_{3}-\mathrm{C}_{4}$ spectrum. For example, in East Africa, early australopithecines derived most of their food from $C_{3}$ sources ${ }^{1,4,6}$ whereas more recent forms such as Paranthropus boisei almost exclusively relied on $\mathrm{C}_{4}$ sources ${ }^{3,5}$. However, significant proportions of $\mathrm{C}_{4}$ sources are recorded in some early forms such as Australopithecus afarensis or Kenyanthropus platyops ${ }^{1,2,7}$. In Central Africa, Australopithecus bahrelghazali represents another example of an early hominin that was sourcing its food in a $\mathrm{C}_{4}$ environment ${ }^{8}$. Another significant result of carbon isotope studies is the marked difference in $\delta^{13} \mathrm{C}$ values between megadont australopithecines, providing evidence that the South African Paranthropus robustus and the East African Paranthropus boisei were exploiting different resources ${ }^{9,17}$. Such results were independently corroborated with microwear texture ${ }^{10,21}$. Nonetheless, other proxies are needed to infer hominin diet beyond the ultimate plant source. Here, we investigate resource use in Turkana Basin hominins from Kenya using calcium and carbon isotopes and discuss their relevance for inferring the evolution of dietary habits in the hominin lineage

Seminal studies on calcium isotopes in vertebrates ${ }^{22}$ recognized a decrease in the ${ }^{44} \mathrm{Ca} /{ }^{42} \mathrm{Ca}$ ratio with increasing trophic level. Subsequent studies supported this trophic level effect, notably in the marine realm ${ }^{23,24}$, but also raised awareness on individual physiological variability influencing $\mathrm{Ca}$ isotope variability ${ }^{25,26}$ or on the insensitivity of $\mathrm{Ca}$ isotope ratios to distinguish between primary and secondary consumers ${ }^{27}$. However, the constant $\delta^{44 / 42} \mathrm{Ca}$ offset of about $-0.6 \%$ from dietary $\mathrm{Ca}$ to bone $\mathrm{e}^{22,28}$ supports the idea of a propagation-related calcium isotope fractionation from one trophic level to another. This pattern reflects a shared physiological feature of all vertebrates including terrestrial and aquatic mammals, as measured in six different species of mammals including foregut and hindgut digestive physiologies (as reviewed $i^{14}$ ). Moreover, this trophic level prediction recently found support as measured in a variety of modern and extinct terrestrial faunas ${ }^{29,30}$. Yet, disentangling dietary sources remains challenging because dietary items possess highly variable calcium concentrations and calcium isotopic compositions as exemplified by plants (as compiled in ${ }^{14,29}$ ), bone ${ }^{31}$ or milk ${ }^{28,32}$. Notably, this last source is ${ }^{44} \mathrm{Ca}$-depleted ${ }^{28}$ and analyzing tissues mineralizing during the pre- to postnatal transition has proved useful to study nursing in modern and fossil hominins ${ }^{32,33}$. Therefore, the isotopic composition of a consumer's tissue is controlled by the mass-weighted isotopic average of all the dietary sources and in our present case, we do not include data from early forming teeth (e.g., first molars). In other words, whether ${ }^{44} \mathrm{Ca}$-enriched or ${ }^{44} \mathrm{Ca}$-depleted, a narrow range of calcium isotopic composition in a consumer tissue may reflect a specialized diet (e.g., late forming teeth of Gorilla, see below and Supplementary Data 1) whereas a scattered distribution should reflect a more complex interplay between resource diversity, isotopic variation in resources, and differential consumption of resources by individuals within a group. As explained above, we favor the hypothesis of a $\mathrm{Ca}$ isotope variability primarily related to diet but other aspects such as speciesdependent physiologic parameters ${ }^{25,26}$ will have to be further explored in future calcium isotope mammal studies. Therefore, in mammals, calcium isotopes can be used to monitor nursing in early formed teeth ${ }^{28,32}$; later formed teeth can provide information on the intake of calcium (Ca) from adult dietary sources ${ }^{29}$.

Here, we report $\mathrm{Ca}$ isotope values for several early hominin species and associated nonhuman primates from the Turkana Basin area. We infer a unique trophic ecology and/or physiology for Paranthropus boisei according to its distinct isotopic distribution.

\section{Results \& discussion}

Ca isotopic variability in modern Gorilla teeth. Teeth belonging to four modern western lowland gorilla (Gorilla gorilla gorilla) individuals from La Lopé National Park, Gabon, analyzed for Ca isotopes ${ }^{33}$, are presented here as a comparison with other hominin and non-hominin primates (Fig. 1 and Supplementary Data 1). Modern gorillas represent an interesting case study so as to test whether a monotonous herbivorous diet is reflected upon the Ca isotopic composition of bioapatite. Two of the sampled

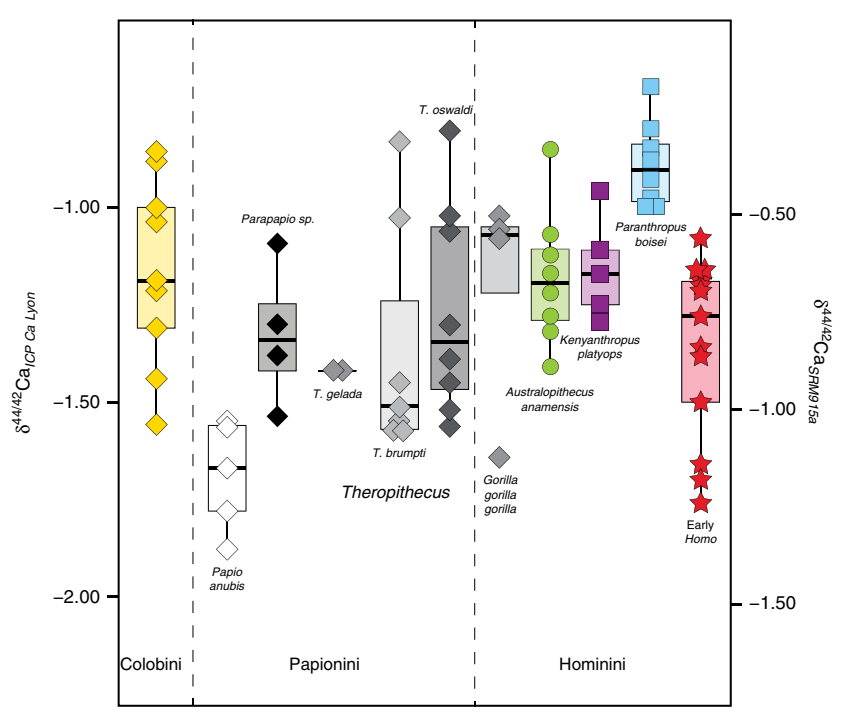

Fig. 1 Box and whisker plots showing the distribution of $\delta^{44 / 42} \mathrm{Ca}$ values (in \%o) between the various non-hominin and hominin primates analyzed in this study as well as some modern representatives (Papio anubis, Theropithecus gelada, and Gorilla gorilla gorilla). Note the ${ }^{44} \mathrm{Ca}$-enriched isotope values of Paranthropus boisei in comparison to other groups. The boxes represent the first and third quartiles with the medians as horizontal lines. The lower and upper whiskers represent $1.5^{*}$ the interquartile range (numbers of biologically independent samples per group: $n=9$ for Colobini; $n=5$ for Papio anubis; $n=4$ for Parapapio sp.; $n=2$ for Theropithecus gelada; $n=7$ for Theropithecus brumpti; $n=8$ for Theropithecus oswaldi; $n=4$ for Gorilla gorilla gorilla; $n=8$ for Australopithecus anamensis; $n=5$ for Kenyanthropus platyops; $n=8$ for Paranthropus boisei; $n=13$ for early Homo). Welch's one-way ANOVA and Kruskal-Wallis tests show significant differences of average means (Welch's one-way ANOVA on all groups except the two T. gelada individuals: 10 groups with a total of 71 biologically independent individual samples, $p$ value $<10^{-4}, F=11.7, \mathrm{df}=9$;

Kruskal-Wallis on all groups: 11 groups with a total of 73 biologically independent individual samples, $p$ value $=0.0005, \mathrm{df}=10) . \delta^{44 / 42} \mathrm{Ca}$ values are expressed both against ICP Ca Lyon (left) and SRM915a (right). Source data are provided as a Source Data file. 
teeth were formed early and include an incisor (G72) with a distinctly low $\delta^{44 / 42} \mathrm{Ca}$ value as well as a first molar (G39) with a surprisingly high $\delta^{44 / 42} \mathrm{Ca}$ value, being indistinct from the two other late forming gorilla teeth (second and third molars) available (Supplementary Data 1). The first molar starts mineralization earlier than the incisor (i.e., before birth) and completes mineralization before the third year (within the fourth year for the incisor $)^{34}$. Nevertheless, it should be stressed that tooth enamel from that first molar was sampled for the entire height of the crown, thus mixing enamel formed in utero with enamel formed during or after completion of weaning. Because such teeth mineralize until 3 year of age after birth ${ }^{35}$, weaning and adult food items other than breast milk (in this case plant material) would have contributed to the high $\delta^{44 / 42} \mathrm{Ca}$ values observed here $^{36}$. It should also be added that dental development is genetically controlled and the huge genetic diversity reported in western lowland gorillas ${ }^{37}$ suggests that a wider spectrum of mineralization patterns exists beyond the published ages reconstructed from histological studies. Therefore, that the first molar (G72) did mineralize later than expected from the dental development models would not be surprising. The two late forming teeth (G40 and G41) display ${ }^{44} \mathrm{Ca}$-enriched compositions and are interpreted as reflecting the post-weaning period of tooth formation during which the individuals were taking their $\mathrm{Ca}$ from adult food ${ }^{33}$. A detailed survey of $\mathrm{Ca}$ isotope variability in gorilla teeth and other modern primates will certainly bring interesting results to discuss physiological versus dietary influence on $\mathrm{Ca}$ isotopic fractionation processes, as currently investigated in humans $26,32,38$.

Ca isotopic variability in non-hominin fossil primates. Our stable calcium isotope values for various hominins and coexisting primates from the Turkana Basin area $(n=69)$ range between $-0.69 \%$ and $-1.88 \%$ (Figs. 1 and 2; Supplementary Data 1). Recently published calcium isotope data for coeval large mammals were shown to preserve their pristine composition, as discussed against elemental concentrations of diagenetic origin of the same samples ${ }^{29}$ (see also Methods). This dataset presents a similar ordering between modern and fossil faunas but also some differences for certain taxa such as suids and saber-tooth cats, interpreted to have had changing dietary ecologies through time ${ }^{29}$.
Papionines have often been considered as analogues to understand dietary preferences of early hominins ${ }^{1}$. The ${ }^{44} \mathrm{Ca}$ depleted isotope values of modern Papio anubis (Fig. 1) are to be considered under the light of the broad feeding preferences in cercopithecines $^{39,40}$. In comparison, the more positive $\mathrm{Ca}$ isotope values of Parapapio sp. invite to consider that extinct taxa may not have been similar in their feeding preferences, although one must take into account that modern Papio anubis has a wide distribution in Africa today and our data cannot reflect such spatial variations. Modern geladas do intensively feed on high altitude $\mathrm{C}_{3}$ grasses ${ }^{41}$ and our $\delta^{44 / 42} \mathrm{Ca}$ values (Supplementary Data 1) for two modern grass-eating Theropithecus gelada $(-1.40 \%)$ are consistent with a grass-eating ecology. Grazers are ${ }^{44} \mathrm{Ca}$-depleted relative to leaf-eaters by about $0.3 \%$ and other modern grazers such as zebras, buffaloes, warthogs, and hippos also display comparably low calcium isotope values that overlap with carnivore values ${ }^{29}$ (Fig. 2). Morphological evidence shows grass-eating adaptations in extinct Theropithecus ${ }^{42}$; carbon isotopes confirm an early dietary adaptation to $\mathrm{C}_{4}$ grasses as an important component of their diet ${ }^{43}$. Here, $\delta^{44 / 42} \mathrm{Ca}$ values for T. brumpti $(-1.36 \pm 0.31 \%, 1 \mathrm{SD}, n=7)$ and T. oswaldi $(-1.26 \pm$ $0.27 \%$, $1 \mathrm{SD}, n=8$ ) are dispersed indicating the availability of a range of isotopically different calcium sources consumed in different proportions by different individuals in each species. Some of those values are not departing much from those of the modern T. gelada, and a grass-eating ecology is a probable dietary hypothesis for some individuals of both fossil species. Nevertheless, this does not exclude other food sources, for example as illustrated here with ${ }^{44} \mathrm{Ca}$-depleted values for several individuals of T. brumpti falling within the same range of values as those of large carnivores (Fig. 2b). T. brumpti was a large-sized theropithecine compared with $T$. oswaldi or to the extant $T$. gelada and contrary to those, T. brumpti was clearly foraging into mixed environments according to $\delta^{13} \mathrm{C}$ values. Given the wide range of $\delta^{44 / 42} \mathrm{Ca}$ values observed in T. brumpti, an omnivorous diet, sometime including bone, is plausible.

Ca isotopic variability in fossil hominins. Australopithecus anamensis and Kenyanthropus platyops could not be distinguished on the basis of calcium isotope values. K. platyops carbon isotope values clearly showed that it foraged in mixed $\mathrm{C}_{3^{-}}$ $\mathrm{C}_{4}$ environments whereas values for $A$. anamensis indicate a
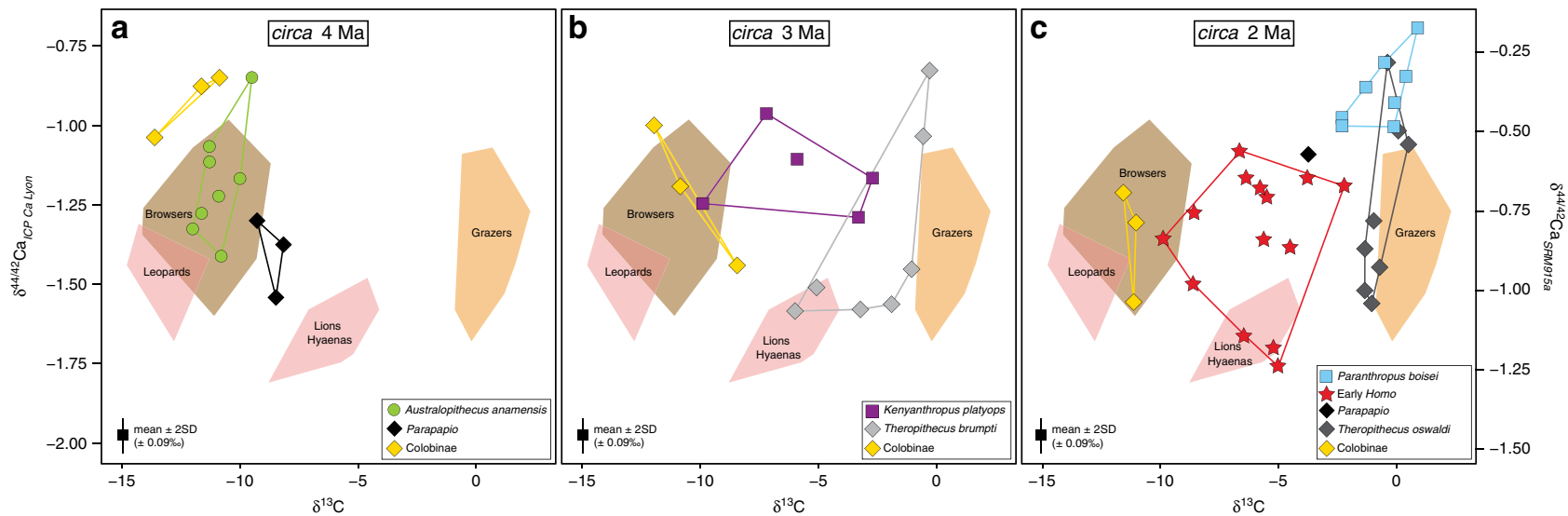

Fig. $2 \delta^{44 / 42} \mathrm{Ca}$ (in \%o) as a function of $\delta^{13} \mathrm{C}$ (in \%o) measured from tooth enamel of fossil hominin and non-hominin primates from the Turkana Basin area, Kenya for different time bins, i.e., circa $4 \mathrm{Ma}$, circa $3 \mathrm{Ma}$ and circa $2 \mathrm{Ma}$ (numbers of biologically independent samples per group: $n=9$ for Colobini; $n=4$ for Parapapio sp.; $n=7$ for Theropithecus brumpti; $n=8$ for Theropithecus oswaldi; $n=8$ for Australopithecus anamensis; $n=5$ for Kenyanthropus platyops; $\boldsymbol{n}=\mathbf{8}$ for Paranthropus boisei; $\boldsymbol{n}=\mathbf{1 3}$ for early Homo). The colored areas represent the domains for previously analyzed extant terrestrial mammal enamel from the Turkana Basin area ${ }^{29}$ ( $n=4$ for leopards; $n=10$ for lions and hyaenas; $n=24$ for browsers; $n=18$ for grazers). $\delta^{44 /}$ ${ }^{42} \mathrm{Ca}$ values are expressed both against ICP Ca Lyon (left) and SRM915a (right). The average 2SD of each Ca isotopic value is represented at the bottom left of each graph. Source data are provided as a Source Data file. 
nearly pure- $\mathrm{C}_{3} \operatorname{diet}^{1}$ similar to Ardipithecus ramidus ${ }^{4}$. Although early studies based on cranial morphology suggested tough/ abrasive food items in the $\operatorname{diet}$ of $A$. anamensis, more recent studies based on microwear and carbon isotopes proposed a diet of soft plant items from the $\mathrm{C}_{3}$ environment ${ }^{1,44}$. Here, the distribution of calcium isotope values in A. anamensis $(-1.18 \pm$ $0.17 \% 0,1 \mathrm{SD}, n=8)$ is not distinctly ${ }^{44} \mathrm{Ca}$-depleted and overlaps much of the modern and fossil East African browser domains (Fig. 2) and indicates that it was foraging on a variety of $\mathrm{C}_{3}$ resources, perhaps fruits or plants, as previously suggested from carbon isotopes ${ }^{1}$. Some individuals of $A$. anamensis may have spent some time in open habitats as indicated by positive $\delta^{18} \mathrm{O}$ values, clearly distinct from the ${ }^{18} \mathrm{O}$-depleted values of Parapapio sp. and colobines (Supplementary Fig. 1, Supplementary Data 1), suggesting a decoupling between food and habitat use.

The $\delta^{44 / 42} \mathrm{Ca}$ values in the early Homo group are dispersed $(-1.36 \pm 0.23 \%$, $1 \mathrm{SD}, n=13)$ and may either indicate wide dietary flexibility, incorporating different sources with varied calcium isotopic values and concentrations, possibly including omnivorous or carnivorous preferences for the most ${ }^{44} \mathrm{Ca}-$ depleted isotope values. In addition, such values may reflect a lack of taxonomic resolution within a diversified early Homo group in the Turkana Basin area containing Homo habilis, Homo rudolfensis, and Homo erectus ${ }^{45}$, and could be due to heterogeneous dietary habits within the genus Homo. Also notable is that early Homo $(-1.36 \pm 0.23 \%$, $1 \mathrm{SD}, n=13)$ and Theropithecus oswaldi $(-1.26 \pm 0.27 \%, n=8)$ have similar calcium isotope values but not carbon isotope values.

The peculiar case of Paranthropus boisei. Paranthropus boisei displays the most ${ }^{44} \mathrm{Ca}$-enriched values of the dataset $(-0.89 \pm$ $0.11 \%, 1 \mathrm{SD}, n=8)$ being statistically different from early Homo (Welch's $t$-test, $p^{* * *}<10^{-4}$ ), Theropithecus oswaldi (Welch's $t$-test, $\left.p^{* *}=0.006\right)$ and from Turkana mammal grazers (Welch's $t$-test, $\left.p^{* * *}<10^{-4}\right)$. That $P$. boisei values do not overlap in a $\delta^{13} \mathrm{C}$ versus $\delta^{44 / 42} \mathrm{Ca}$ space with any other hominins and non-hominin grazers (Figs. 1 and 2; Supplementary Data 2) adds to the uniqueness of this taxon, as previously highlighted in the literature with morphological, microwear, or carbon isotopic studies.

$P$. boisei possesses a unique tooth morphology with thick enamel and flatten occlusal surfaces when worn, and dental microwear studies do suggest a diet of soft plant items ${ }^{21}$. If leaves appear to be a good dietary candidate, $\mathrm{C}_{4}$ leaves other than blades from grasses or sedges are not obviously identified in modern ecosystems. Theropithecus gelada cannot be considered a modern primate analogue for $P$. boisei, given their differences in $\delta^{44 / 42} \mathrm{Ca}$ values. A modern primate analogue for $P$. boisei that would feed on $\mathrm{C}_{4}$ vegetation other than grass or sedge does not exist. Gorillas could be viewed as a remote plant-eating analogue. The two lateforming modern western lowland gorilla teeth from La Lopé in Gabon display calcium isotope values around $-1.05 \%$ (Supplementary Data 1$)^{33}$, comparable with the values of $P$. boisei. Although those gorillas feed on fruits, leaves, and ants, these resources arise from $\mathrm{C}_{3}$, not $\mathrm{C}_{4}$ plants ${ }^{11}$. While dicot leaves and fruits are ${ }^{44} \mathrm{Ca}$-enriched, the only dicot leaves that follow the $\mathrm{C}_{4}$ photosynthetic pathway are represented by forbs, which would be found in relatively wet environments ${ }^{46}$ and could be a dietary candidate for $P$. boisei according to oxygen isotope composition of $P$. boisei teeth suggesting water dependency ${ }^{5}$. Conducting a calcium isotope survey of such plants but also of $\mathrm{C}_{4}$ sedges, especially in including plant parts that are known to fractionate differently ${ }^{47}$, would certainly add relevant data to better tackle this problem. On the other hand, we cannot exclude that both $G$. gorilla and $P$. boisei had physiological similarities that would lead to ${ }^{44} \mathrm{Ca} /{ }^{42} \mathrm{Ca}$ values that are enriched relative to other primates.
Whatever the exact dietary component or physiological specificity of $P$. boisei was, this species remains remarkable for exhibiting ${ }^{44} \mathrm{Ca}$-enriched tooth enamel within a narrow range of isotope values, which most likely reflect a specialized diet on items with low isotopic variability ${ }^{48}$ possibly associated to a physiology different than other primates. The range of calcium isotope values of $P$. boisei not only differs from other hominins of the Turkana Basin, it also differs from that of its South African congener $P$. robustus, which shows lower calcium isotope values ${ }^{33}$ (Fig. 3). Interestingly, P. robustus and A. africanus do not differ in $\delta^{13} \mathrm{C}$ values ${ }^{9}$, nor do they differ in $\delta^{44 / 42} \mathrm{Ca}$ values ${ }^{33}$ (Fig. 3). $P$. robustus was interpreted to have had a flexible diet together with the contemporaneous early Homo from South Africa ${ }^{9,49}$, a hypothesis that seems corroborated by the overlap of calcium isotope values of P. robustus with early Homo and A. africanus ${ }^{33}$. From our study as well as previous ones based on $\delta^{13} \mathrm{C}$ values ${ }^{1}$ or tooth microwear $^{21}$, the emerging picture could be that of $P$. boise in East Africa with a specialized diet versus $P$. robustus in South Africa with a flexible diet ${ }^{9,49}$. These results confirm discrepancies between diets but apparently shared masticatory function and weaken the case for Paranthropus monophyly based solely on dentognathic features ${ }^{50}$.

In summary, calcium isotope ratios in a survey of hominin lineages in East Africa show that $P$. boisei has a unique ${ }^{44} \mathrm{Ca} /{ }^{42} \mathrm{Ca}$

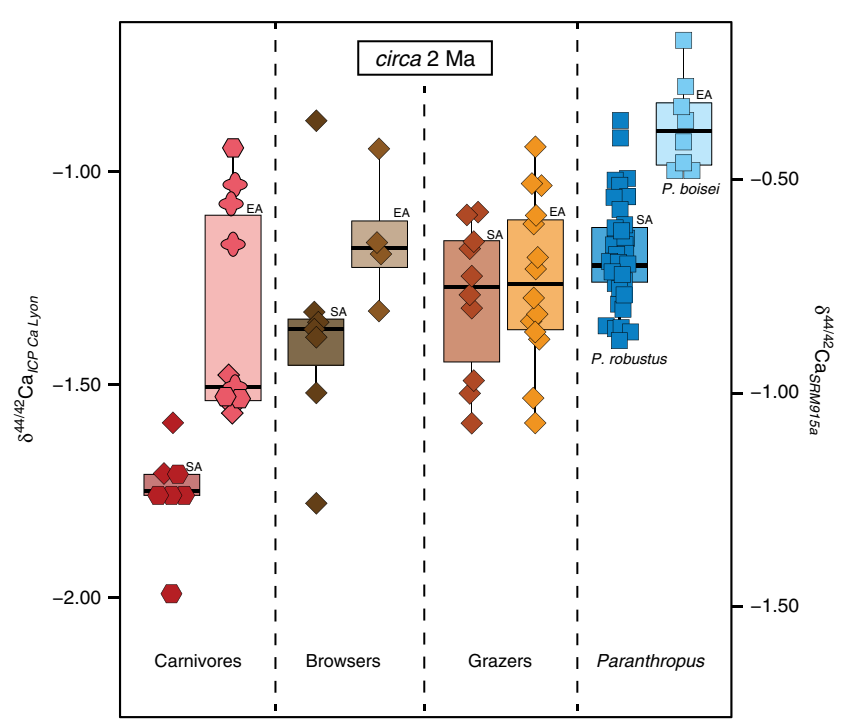

Fig. 3 Box and whisker plots showing the distribution of $\delta^{44 / 42} \mathrm{Ca}$ values (in \%o) between Turkana Basin Paranthropus boisei, South African Paranthropus robustus ${ }^{33}$ and associated mammal faunas. Data for grazers, browsers, and carnivores are from Martin et al. ${ }^{29}$ and Tacail et al. ${ }^{33}$. EA East Africa, SA South Africa. Values selected for representatives of the associated-fauna include only those values for organisms circa $2 \mathrm{Ma}$; for this reason, the browser category may appear underrepresented and the apparent difference may reflect specific dietary differences rather than differences in the substrate isotope baseline. Note that carnivore values in EA are dispersed as explained by a dataset that includes sabertooth felids. The boxes represent the first and third quartiles with the medians as horizontal lines. The lower and upper whiskers represent $1.5{ }^{*}$ the interquartile range (numbers of biologically independent samples per group: $n=7$ for South African carnivores; $n=10$ for East African carnivores; $n=7$ for South African browsers; $n=4$ for East African browsers; $n=10$ for South African grazers; $n=14$ for East African grazers; $n=38$ for Paranthropus robustus; $n=8$ for Paranthropus boisei). $\delta^{44 / 42} \mathrm{Ca}$ values are expressed both against ICP Ca Lyon (left) and SRM915a (right). Source data are provided as a Source Data file. 
ratio compared with other hominins including the South African $P$. robustus, all of which have similar ratios to each other but not to $P$. boisei. This calcium isotope difference could be due to differences in diet, or in physiology, and remains a unique character of $P$. boisei compared with other hominins.

\section{Methods}

Fossil samples. Fossil samples were available from the collections of the National Museums of Kenya and the Turkana Basin Institute. Those fossil samples are part of a paleoecology project reported in Cerling et al. ${ }^{51}$. Powdered enamel was collected using a low-speed dental drill along the broken surfaces of tooth enamel. Each sample represents an average of the crown height in order to provide enough material for the published carbon isotope analyses initially envisioned. 100-200 $\mu \mathrm{g}$ of powder per sample was used for $\mathrm{Ca}$ isotope purification.

Modern samples. Two geladas (Theropithecus gelada) individuals were made available from the historical collections of the Musée des Confluences in Lyon, France (MHNL). The precise Ethiopian origin of the specimens is not provided on the labels. Specimen MHNL 50001812 is a male individual and was donated to the Museum by Claudius Côte on the 13th of august 1929. Specimen MHNL 50001729 is a male individual from Abyssinia and was bought from Mr. Siepi, then a naturalist in Marseille on the 3rd of march 1925.

Sample chemistry. The chemical processing of the samples follows the method described in details in Martin et al. ${ }^{29}$ and Tacail et al ${ }^{33,52}$. Briefly, enamel samples were dissolved in $300 \mu \mathrm{l}$ of suprapure $1 \mathrm{M} \mathrm{HCl}$ acid and were subsequently processed through AG50X-W12 cation exchange resin in $1 \mathrm{M} \mathrm{HCl}$ medium to dispose of sample matrix. $\mathrm{Ca}$ and $\mathrm{Sr}$ fractions were collected in $6 \mathrm{M} \mathrm{HCl}$ medium. $\mathrm{Ca}$ fractions were then separated from Sr by loading samples onto columns filled with Sr-specific resin (Eichrom Sr-Spec) in suprapure $2 \mathrm{M} \mathrm{HNO}_{3}$ medium. Blanks for the whole procedure did not exceed $100 \mathrm{ng} \mathrm{Ca}$.

Isotopic measurements. Calcium isotope abundance ratios $\left({ }^{44} \mathrm{Ca} /{ }^{42} \mathrm{Ca}\right.$ and ${ }^{43} \mathrm{Ca} /$ ${ }^{42} \mathrm{Ca}$ ) were measured using a multi-collector ICP-MS (MC-ICP-MS, Neptune Plus, Thermo). After purification, Ca samples were dissolved in ultrapure $0.05 \mathrm{M} \mathrm{HNO}_{3}$ and $\mathrm{Ca}$ concentration was set at $2 \mathrm{ppm}$ for all samples and standards. All $\mathrm{Ca}$ isotope compositions are expressed using the 'delta' notation defined as follows for the ${ }^{44} \mathrm{Ca} /{ }^{42} \mathrm{Ca}$ ratio:

$$
\delta^{44 / 42} \mathrm{Ca}=\left[\frac{\left({ }^{44} \mathrm{Ca} /{ }^{42} \mathrm{Ca}\right)_{\text {sample }}}{\left({ }^{44} \mathrm{Ca} /{ }^{42} \mathrm{Ca}\right)_{\text {ICP Ca Lyon }}}-1\right] \times 1000,
$$

where $\left({ }^{44} \mathrm{Ca} /{ }^{42} \mathrm{Ca}\right)_{\text {sample }}$ and $\left({ }^{44} \mathrm{Ca} /{ }^{42} \mathrm{Ca}\right)_{\text {ICP Ca Lyon }}$ are the Ca isotope abundance ratios measured in sample and ICP Ca Lyon reference standard, respectively. The ICP Ca Lyon standard, used as a bracketing standard, is a Specpure Ca plasma standard solution (Alfa Aesar) ${ }^{12,24,30,32,33,52-55}$. All newly reported samples were measured as part of the same batches as the samples reported in Martin et al. ${ }^{29}$, i.e., in June and August 2016 and in June and July 2017. A single concentrated solution of NIST SRM 1486 was repeatedly purified and measured in the same batches as the samples to control for accuracy. In order to ease comparison of our dataset with other $\mathrm{Ca}$ isotope studies from the literature, all values obtained in this study are also expressed relative to SRM915a standard (Supplementary Data 1) using the constant difference of $-0.518 \pm 0.025 \%$ (2SD) as calibrated by analyzing four international standards previously reported against SRM915a and repeatedly measured against ICP Ca Lyon (see Supplementary Information in Martin et al. ${ }^{29}$ ). All statistical tests on the Ca isotope data were performed with the R "stats" package $^{56}$

Quality. Samples were randomly measured during the ICP-MS sessions that served to build the dataset published on the modern and fossil Turkana fauna in Martin et al. ${ }^{29}$. All samples fall on a calcium mass fractionation line with a slope of $0.519 \pm$ $0.018 \%$ (2SE) (Supplementary Fig. 2) in good agreement with the 0.5067 slope predicted by the linear approximation of exponential mass-dependent fractionation. Independent measurements of NIST SRM 1486 standards yielded a mean value of: $-1.047 \pm 0.13 \% 2 \mathrm{SD}(n=101)$. These values are the same as those measured in the same laboratory at LGLTPE ${ }^{12,24,30,32-34,52-55}$ and agree well with previously published values from other laboratories ${ }^{31,57-59}$.

Diagenesis. It is well known that diagenetic processes can alter the original isotopic composition of mineralized tissues. That $\mathrm{Ca}$ is a major constituent of bioapatite (at a concentration of about $35-40 \%$ in weight) represents a solid reason to investigate its isotopic composition in fossil bone and teeth as old as the Cretaceous ${ }^{30,31,53}$. Here, before chemical purification of $\mathrm{Ca}$ isotopes, all samples underwent the standard protocol that is applied for carbon isotopic analyses by removing potential secondary carbonates ${ }^{51}$. Measuring trace element concentrations requires more than half a milligram-when such elements are present - and therefore necessitates large quantities of sample powder at the cost of precious samples, such as the hominin teeth analyzed in the present study. In this study, our average sample weight uptake was about $100 \mu \mathrm{g}$, which is suitable for $\mathrm{Ca}$ isotope analysis but obviously not for trace element concentrations. Correlations between trace elements of diagenetic origin and Ca isotopic compositions were assessed in a previous study of fossil mammals from the same Turkana Basin localities ${ }^{29}$ as those of the hominins analyzed in the present study. We concluded that the impact of diagenesis on our Ca isotopic measurements was minimal ${ }^{29}$ and by extension, we consider such conclusions applicable to the present hominin dataset.

Comparing East African versus South African datasets. Because a substrate effect cannot be excluded on the fractionation of calcium isotopes, we used associated faunal calcium isotope compositions ${ }^{29,33}$ to serve as a baseline. This issue has not been explored in detail yet ${ }^{29}$ but it is worth repeating here that $\mathrm{Ca}$ isotopic composition in rocks is rather homogenous ${ }^{60}$ and a substrate effect may not be pre-eminent in vertebrate tissues. The Turkana fossil assemblage circa $2 \mathrm{Ma}$ includes six felids and four hyaenids calcium isotope values more variable than the range of values of the seven carnivores from South Africa that also includes felids and hyaenids. This dispersion in $\mathrm{Ca}$ isotope values is explained by the presence in the Turkana dataset of saber tooth felids, whose diet was specialized as previously discussed ${ }^{29}$. The fossil browsers from Turkana $(-1.16 \%, n=4)$ versus browsers from South Africa $(-1.38 \%, n=7)$ show different values. Browsers from South Africa consist of one genus only, Tragelaphus, which is known in modern South Africa to include about one-third of $\mathrm{C}_{4}$ component in its $\operatorname{diet}^{61}$ and might explain some of its values to be ${ }^{44} \mathrm{Ca}$-depleted. The low number of browsers from East Africa that includes two giraffids and two bovids does not permit to satisfyingly compare both browser datasets. Finally, the fossil grazers consist of a larger dataset, taxa from Turkana $(-1.25 \%, n=14)$ versus grazers from South Africa $(-1.30 \%$, $n=10$ ) gave consistent values indicating that beyond some variability that may arise from seasonal variation into food items (although this is restrained by the sampling protocol-see above), nursing processes or other unconstrained environmental processes, it is reasonable to compare both South African and East African palaeoenvironments.

Reporting summary. Further information on research design is available in the Nature Research Reporting Summary linked to this article.

\section{Data availability}

The authors declare that all data supporting the findings of this study are included in this published article and its supplementary information files. Source data are provided with this paper. $\mathrm{Ca}, \mathrm{O}$ and $\mathrm{C}$ isotope data of modern and fossil non-primates used in Fig. 2 and Supplementary Figs. 2 and 3 are available from the public repository HAL at https:// hal-udl.archives-ouvertes.fr/hal-02568580/. Ca isotope data of fossil taxa from South Africa used in Fig. 3 are available from the open access dataset at https://advances. sciencemag.org/content/5/8/eaax3250/tab-figures-data. Source data are provided with this paper.

Received: 7 February 2020; Accepted: 30 June 2020; Published online: 17 July 2020

\section{References}

1. Cerling, T. E. et al. Stable isotope-based diet reconstructions of Turkana Basin hominins. Proc. Natl. Acad. Sci. USA 110, 10501-10506 (2013).

2. Wynn, J. G. et al. Geological and palaeontological context of a Pliocene juvenile hominin at Dikika, Ethiopia. Nature 443, 332-336 (2006).

3. van der Merwe, N., Masao, F. \& Bamford, M. Isotopic evidence for contrasting diets of early hominins Homo habilis and Australopithecus boisei of Tanzania. South Afr. J. Sci. 104, 153-155 (2008).

4. White, T. D. et al. Ardipithecus ramidus and the paleobiology of early hominids. Science 326, 64-86 (2009).

5. Cerling, T. E. et al. Diet of Paranthropus boisei in the early Pleistocene of East Africa. Proc. Natl. Acad. Sci. USA 108, 9337-9341 (2011).

6. Henry, A. G. et al. The diet of Australopithecus sediba. Nature 487, 90-93 (2012)

7. Levin, N., Haile-Selassie, Y., Frost, S. R. \& Saylor, B. Z. Dietary change among hominins and cercopithecids in Ethiopia during the early Pliocene. Proc. Natl. Acad. Sci. USA 112, 12304-12309 (2015).

8. Lee-Thorp, J. et al. Isotopic evidence for an early shift to C4 resources by Pliocene hominins in Chad. Proc. Natl. Acad. Sci. USA 109, 20369-20372 (2012).

9. Sponheimer, M. et al. Isotopic evidence for dietary variability in the early hominin Paranthropus robustus. Science 314, 980-982 (2006).

10. Scott, R. S. et al. Dental microwear texture analysis reflects diets of living primates and fossil hominins. Nature 436, 693-695 (2005). 
11. Martin, J. E., Vance, D. \& Balter, V. Magnesium stable isotope ecology using mammal tooth enamel. Proc. Natl. Acad. Sci. USA 112, 430-435 (2015).

12. Martin, J. E., Tacail, T. \& Balter, V. Non-traditional isotope perspectives in vertebrate palaeobiology. Palaeontology 60, 485-502 (2017).

13. Jaouen, K. \& Pons, M. L. Potential of non-traditional isotope studies for bioarchaeology. Archaeol. Anthropol. Sci. 9, 1389-1404 (2017).

14. Tacail, T., Le Houedec, S. \& Skulan, J. L. New frontiers in calcium stable isotope geochemistry: perspectives in present and past vertebrate biology. Chem. Geol. https://doi.org/10.1016/j.chemgeo.2020.119471 (2020).

15. Bourgon, N. et al. Zinc isotopes in Late Pleistocene fossil teeth from a Southeast Asian cave setting preserve paleodietary information. Proc. Natl. Acad. Sci. USA 117, 4675-4681 (2020).

16. Balter, V. et al. Were Neandertalians essentially carnivores? Sr and Ba preliminary results of the mammalian palaeobiocoenosis of Saint-Césaire. $C$. R. Acad. Sci. IIA 332, 59-65 (2001).

17. Sponheimer, M. \& Lee-Thorp, J. A. Enamel diagenesis at South African Australopith sites: implications for paleoecological reconstruction with trace elements. Geochim. Cosmochim. Acta 70, 1644-1654 (2006).

18. Balter, V., Braga, J., Télouk, P. \& Thackeray, J. F. Evidence for dietary change but not landscape use in South African early hominins. Nature 489, 558-560 (2012).

19. Joannes-Boyau, R. et al. Elemental signatures of Australopithecus africanus teeth reveal seasonal dietary stress. Nature 572, 112-115 (2019).

20. Cerling, T. E. et al. Global vegetation change through the Miocene/Pliocene boundary. Nature 389, 153-158 (1997).

21. Ungar, P. S., Grine, F. E. \& Teaford, M. F. Dental microwear and diet of the Plio-Pleistocene hominin Paranthropus boisei. PLoS ONE 3, e2044 (2008).

22. Skulan, J. \& DePaolo, D. J. Calcium isotope fractionation between soft and mineralized tissues as a monitor of calcium use in vertebrates. Proc. Natl. Acad. Sci. USA 96, 13709-13713 (1999).

23. Clementz, M. T., Holden, P. \& Koch, P. L. Are calcium isotopes a reliable monitor of trophic level in marine settings? Intl. J. Osteoarchaeol. 13, 29-36 (2003).

24. Martin, J. E., Tacail, T., Adnet, S., Girard, C. \& Balter, V. Calcium isotopes reveal the trophic position of extant and fossil elasmobranchs. Chem. Geol. 415, 118-125 (2015).

25. Reynard, L. M., Henderson, G. M. \& Hedges, R. E. M. Calcium isotope ratios in animal and human bone. Geochim. Cosmochim. Acta. 74, 3735-3750 (2010).

26. Li, Q., Thirwall, M. \& Müller, W. Ca isotopic analysis of laser-cut microsamples of (bio)apatite without chemical purification. Chem. Geol. 422, 1-12 (2016).

27. Melin, A. D. et al. Calcium and carbon stable isotope ratios as paleodietary indicators. Am. J. Phys. Anthropol. 154, 633-643 (2014).

28. Chu, N. C., Henderson, G. M., Belshaw, N. S. \& Hedges, R. E. Establishing the potential of $\mathrm{Ca}$ isotopes as proxy for consumption of dairy products. Appl. Geochem. 21, 1656-1667 (2006).

29. Martin, J. E., Tacail, T., Cerling, T. E. \& Balter, V. Calcium isotopes in enamel of modern and Plio-Pleistocene East African mammals. Earth Planet. Sci. Lett. 503, 227-235 (2018)

30. Hassler, A. et al. Calcium isotopes offer clues on resource partitioning among Cretaceous predatory dinosaurs. Proc. Roy. Soc. B 285, 20180197 (2018).

31. Heuser, A., Tütken, T., Gussone, N. \& Galer, S. J. Calcium isotopes in fossil bones and teeth-Diagenetic versus biogenic origin. Geochim. Cosmochim. Acta. 75, 3419-3433 (2011).

32. Tacail, T. et al. Assessing human weaning practices with calcium isotopes in tooth enamel. Proc. Natl. Acad. Sci. USA 114, 6268-6273 (2017).

33. Tacail, T. et al. Calcium isotopic patterns in enamel reflect different nursing behavior among South African early hominins. Sci. Adv. 5, eeax3250 (2019). https://doi.org/10.1126/sciadv.aax3250.

34. Beynon, A. D., Dean, M. C. \& Reid, D. J. Histological study on the chronology of the developing dentition in Gorilla and Orangutan. Am. J. Phys. Anthropol. 86, 189-203 (1991).

35. Kelley, J. \& Schwartz, G. T. Dental development and life history in living African and Asian apes. Proc. Natl. Acad. Sci. 107, 1035-1040 (2010).

36. Fletcher, A. \& Nowell, A. The development of feeding behaviour in wild western lowland gorillas (Gorilla gorilla gorilla). Behaviour 145, 171-193 (2008).

37. Prado-Martinez, J. et al. Great ape genetic diversity and population history. Nature 499, 471-475 (2014).

38. $\mathrm{Li}, \mathrm{Q}$. et al. Spatially-resolved $\mathrm{Ca}$ isotopic and trace element variations in human deciduous teeth record diet and physiological change. Env. Archaeol. In Press, 1-10, https://doi.org/10.1080/14614103.2020.1758988 (2020).

39. Scott, R. S., Teaford, M. F. \& Ungar, P. S. Dental microwear texture and anthropoid diets. Am. J. Phys. Anthropol. 147, 551-579 (2012).

40. Martin, F. et al. Dietary niches of terrestrial cercopithecines from the PlioPleistocene Shungura Formation, Ethiopia: evidence from Dental Microwear Texture Analysis. Sci. Rep. 8, 14052 (2018).

41. Fashing, P. J., Nguyen, N., Venkataraman, V. V. \& Kerby, J. T. Gelada feeding ecology in an intact ecosystem at Guassa, Ethiopia: variability over time and implications for theropith and hominin dietary evolution. Am. J. Phys. Anthropol. 155, 1-16 (2014).

42. Souron, A. Morphology, diet, and stable carbon isotopes: on the diet of Theropithecus and some limits of uniformitarianism in paleoecology. Am. J. Phys. Anthropol. 166, 261-267 (2018).

43. Cerling, T. E., Chritz, K. L., Jablonski, N. G., Leakey, M. G. \& Manthi, F. K. Diet of Theropithecus from 4 to 1 Ma in Kenya. Proc. Natl. Acad. Sci. USA 110 10507-10512 (2013).

44. Grine, F. E., Sponheimer, M., Ungar, P. S., Lee-Thorp, J. \& Teaford, M. F. Dental microwear and stable isotopes inform the paleoecology of extinct hominins. Am. J. Phys. Anthropol. 148, 285-317 (2012).

45. Leakey, M. G. et al. New fossils from Koobi Fora in northern Kenya confirm taxonomic diversity in early Homo. Nature 488, 201-204 (2012).

46. Peters, C. R. \& Vogel, J. C. Africa's wild C4 plant foods and possible early hominid diets. J. Hum. Evol. 48, 219-236 (2005).

47. Schmitt, A.-D. 2016. Earth-Surface Ca Isotopic Fractionations. In Calcium Stable Isotope Geochemistry (eds Tipper, E. T., Schmitt, A. D. and Gussone, N.) 145-172. (Springer, Berlin Heidelberg, 2016).

48. Yeakel, J. D., Bhat, U., Elliott Smith, E. A. \& Newsome, S. Exploring the isotopic niche: isotopic variance, physiological incorporation, and the temporal dynamics of foraging. Front. Ecol. Evol. 4, https://doi.org/10.3389/ fevo.2016.00001 (2016).

49. Wood, B. \& Strait, D. Patterns of resource use in early Homo and Paranthropus. J. Hum. Evol. 46, 119-162 (2004).

50. Wood, B. \& Schroer, K. Paranthropus: where do things stand? in Human paleontology and prehistory (eds Marom, A. and Hovers, E.) 95-107 (Springer, Cham, 2017).

51. Cerling, T. E. et al. Dietary changes of large herbivores in the Turkana Basin, Kenya from 4 to 1 million years ago. Proc. Natl. Acad. Sci. USA 112, 11467-11472 (2015)

52. Tacail, T., Albalat, E., Télouk, P. \& Balter, V. A simplified protocol for measurement of $\mathrm{Ca}$ isotopes in biological samples. J. Anal. Atom. Spectrom. 29, 529-535 (2014).

53. Martin, J. E. et al. Calcium isotopic evidence for vulnerable marine ecosystem structure prior to the K/Pg extinction. Curr. Biol. 27, 1641-1644 (2017).

54. Balter, V. et al. Calcium stable isotopes place Devonian conodonts as first level consumers. Geochem. Persp. Lett. 10, 36-39 (2019).

55. Tacail, T., Télouk, P. \& Balter, V. Precise analysis of calcium stable isotope variations in biological apatites using laser ablation MC-ICPMS. J. Anal. Atom. Spectrom. 31, 152-162 (2016).

56. R Core Team. R: A language and environment for statistical computing. $\mathrm{R}$ Foundation for Statistical Computing, Vienna, Austria. https://www.R-project. org/ (2018)

57. Heuser, A., Eisenhauer, A., Scholz-Ahrens, K. E. \& Schrezenmeir, J. Biologica fractionation of stable $\mathrm{Ca}$ isotopes in Göttingen minipigs as a physiological model for Ca homeostasis in humans. Isotopes Environ. Health Stud. $\mathbf{5 2}$ 633-648 (2016).

58. Heuser, A. \& Eisenhauer, A. The calcium isotope composition $\left(\delta^{44 / 40} \mathrm{Ca}\right)$ of NIST SRM 915b and NIST SRM 1486. Geostand. Geoanal. Res. 32, 311-315 (2008).

59. Heuser, A., Schmitt, A., Gussone, N. \& Wombacher, F. Analytical Methods. In Calcium Stable Isotope Geochemistry. 23-73 (Springer, Berlin, Heidelberg, 2016).

60. Tipper, E.T., Schmitt, A. \& Gussone, N. Global Ca Cycles: Coupling of Continental and Oceanic Processes. In Calcium Stable Isotope Geochemistry. 173-222 (Springer, Berlin, Heidelberg, 2016). https://doi.org/10.1007/978-3540-68953-9_6.

61. Sponheimer, M. et al. Diets of southern African Bovidae: stable isotope evidence. J. Mammal. 84, 471-479 (2003).

\section{Acknowledgements}

We thank the National Museums of Kenya and the Kenyan Government for permission to work on this material, and Meave G. Leakey and F. Kyalo Manthi for assistance throughout our studies of hominin diets. We thank Didier Berthet and the Musée des Confluences de Lyon for permission to sample specimens. This work was funded by NSF grant 1740383 and a University of Utah Seed Grant; to T.E.C. and CNRS (Tellus-Rift and INSU INTERRVIE) and ENS-Lyon to J.E.M. and V.B.

\section{Author contributions}

V.B., T.E.C., J.B., T.T., and J.E.M. conceived the study. J.E.M., T.T., T.E.C., and V.B. prepared the samples and measured the isotopic compositions. All co-authors analyzed and discussed the raw data. J.E.M. prepared the draft paper, which was edited by all the co-authors.

\section{Competing interests}

The authors declare no competing interests. 


\section{Additional information}

Supplementary information is available for this paper at https://doi.org/10.1038/s41467020-17427-7.

Correspondence and requests for materials should be addressed to J.E.M.

Peer review information Nature Communications thanks Shara Bailey, Renaud JoannesBoyau and the other, anonymous, reviewer(s) for their contribution to the peer review of this work.

Reprints and permission information is available at http://www.nature.com/reprints

Publisher's note Springer Nature remains neutral with regard to jurisdictional claims in published maps and institutional affiliations. (c) (i) Open Access This article is licensed under a Creative Commons Attribution 4.0 International License, which permits use, sharing, adaptation, distribution and reproduction in any medium or format, as long as you give appropriate credit to the original author(s) and the source, provide a link to the Creative Commons license, and indicate if changes were made. The images or other third party material in this article are included in the article's Creative Commons license, unless indicated otherwise in a credit line to the material. If material is not included in the article's Creative Commons license and your intended use is not permitted by statutory regulation or exceeds the permitted use, you will need to obtain permission directly from the copyright holder. To view a copy of this license, visit http://creativecommons.org/ licenses/by/4.0/.

(C) The Author(s) 2020 